\title{
Leishmania braziliensis: aislamiento de lesiones por inoculación de hámsteres con o sin adición de lisado de glándulas salivares de Lutzomyia youngi*
}

\author{
Leishmania braziliensis: isolation of lesions by inoculation of hamsters with \\ and without the addition of salivary gland lysates of Lutzomyia youngi
}

\author{
Elina Rojas, Jose V. Scorza
}

Centro Trujillano de Investigaciones "José W. Torrealba" - Venezuela

\begin{abstract}
Homogeneizados de blopsias de lesiones cutáneas de 50 casos de leishmaniasis tegumentaria de Trujillo, Venezuela, han sldo inoculados en hámsteres machos. Se ha comparado la infectvidad de Leishamania braziliensis, de homogeneizados simples, con la de los mezclados con lisado de glándula salival de Lutzomyia youngi, registrandose un $58,5 \%$ de infecciones para una media de 12 semanas de prepatencia con los homogeneizados simples, contra $92 \%$ de infecciones con una media de 3 semanas de prepatencia, cuando cada uno de los inóculos de homogeneizado se mezcló con lisado equivalente al de una glándula salival de flebótomo.
\end{abstract}

Leishmania braziliensis, patogenicidad. Psychodidae. Glándulas salivares.

\section{Introducción}

La leishmaniasis cutánea localizada es una endemia frecuente en Venezueia, particularmente en la ciudad de Trujillo de la Región de los Andes (Scorza et al. ${ }^{11}, 1985$ ), donde en los últimos doce años se han atendido 675 casos urbanos y suburbanos, en una población de 57.846 habitantes para 1990.

Se desconoce la distribución urbana del agente etiologico aunque se sabe que circulan localmente cepas de Leishmania braziliensis braziliensis y de L. b. guyanensis (Scorza \& Rojas ${ }^{12}, 1990$ ).

Para aislar cepas de pacientes de la localidad se inoculó subcutáneamente triturados de biopsias de lesiones en el tarso de hámsteres, con la adición de lisado de glándulas salivares de Latzomyia youngi, principal vector en la ciudad (Scorza et al., ${ }^{10}$ 1984). Con el objetivo de comparar la infectividad de los parásitos en estos animales, se desarrolló un estudio experimental con inóculos de leishmania de 50 pacientes, mezclandolos o no con lisado de glándulas salivales de Lutzomyia youngi.

Se ha demostrado que la inoculación de una mezcla de promastigotos de $L$. major con lisado de glándulas salivales de Lu. longipalpis, en ratones, incrementa la infectividad del inoculo (Titus \& Ribeiro ${ }^{14}, 1988$ ). La respuesta inflamatoria en el sitio de inoculación en tarsos de hámsteres, de promastigotos de $L$. chagasi mezclados con lisado de gládulas de $L$. long $i$ palpis, aumenta la fagocitosis de los parásitos por los macrófagos (Laurenti et al., ${ }^{3}$ 1992).

La presencia de promastigotos metaciclicos en el conducto hipofaríngeo de $L u$, youngi experimentalmente infectados con $L$. mexicana y L. braziliensis (Rojas \& Scorza ${ }^{8}, 1991$ ), sustenta el papel de la saliva en la inoculación de los parásitos (James \& Rossignol2 2 1991).

En el presente trabajo se describen resultados que comparan la infectividad en hámsteres de inóculos de leishmanias de lesiones de cincuenta pacientes, mezclandolos o no, con lisado de glándulas salivales de $L u$. youngi.

\footnotetext{
* Investigación subsidiada por el Consejo de Desarrollo Cientifico, Hamanistico y Tecnológico. ULA y T de la Universidad de los Andes (Proyecto NURR-c-60-88).

Separatas/Reprints: Elina Rojas - Apartado 100 - Trujillo - Venezuela

Recebido en 21.6.1994. Aprobado en 24.11.1994.
} 


\section{Material y Metodos}

Pacientes - 50 casos clínicos de leishmaniasis cutánea localizada atendidos en la Consulta Externa del Centro de Investigaciones "José W. Torrealba" de Trujillo, Venezuela, durante 1992-1994, diagnosticados parasitológicamente por examen microscópico. Se incluyen 25 hombres y 25 mujeres con edades comprendidas entre 8 y 61 años.

Hamsteres - Hámsteres machos de seis semanas, dos por cada paciente. Provienen del Bioterio de la Universidad de los Andes, y son mantenidos separados, por pares, con alimento concentrado para ratas y agua ad libitum.

Lisado de glándulas salivales de Lu. youngi- Hembras silvestres de $L u$. youngi, capturadas en una localidad no endémica para leishmaniasis, se disecaron en solución hipotônica de $\mathrm{NaCl}(0,6 \%)$ para separar las nuliparas (Marquez \& Scorza ${ }^{4}, 1982$ ). De estas nulíparas, en fechas diferentes, se extrajeron las glándulas salivales por lotes de 10 hembras, para suspenderlas en 1,0 ml de solución salina isotônica, congelándolas y descongelándolas tres veces para conservarlas a $-8^{\circ} \mathrm{C}$.

Inoculación de hamsteres - Cuando un paciente presentó mas de una úlcera, selecciono siempre la lesion con la apariencia de ser la menos contaminada para extraer un fragmento del borde de la úlcera, previa anestesia subcutánea con xilocaína. Con cada biopsia de cada paciente se preparou dos inóculos homogeneizados, tomando aproximadamente $50 \mathrm{mg}$ de tejido para triturarlo con un mortero de porcelana en $0,5 \mathrm{ml}$ de solución salina.

Inmediatamente, en la cara dorsal del tarso derecho de un hamster, se inyectó subcutáneamente $0,05 \mathrm{ml}$ de la suspensión del homogeneizado con $0,05 \mathrm{ml}$ de solución isotónica. En el tarso izquierdo del mismo animal se inyectó 0,1 $\mathrm{ml}$ de solución salina. Similarmente, en otro hamster experimental, se inoculo una mezcla de $0,05 \mathrm{ml}$ de lisado de glándula salival de $L u$. youngi, con $0,05 \mathrm{ml}$ del homogeneizado de la biopsia en el tarso derecho y $0,1 \mathrm{ml}$ de solución salina en el tarso izquierdo.
Seguimiento de los animales experimentales - A partir de quince días de la inoculación, cuando hubo desaparecido la inflamación inespecífica producida por el trauma de la inyección, se examinaron semanalmente los animales durante los primeros seis meses y luego quincenalmente, hasta detectar la aparición de una induración en el sitio de inoculación en la cara dorsal del tarso derecho. Se anotó la fecha de aparición de la lesión tarsal y se confirmó su origen parasitario por examen microscópico de improntas de cada lesión en los animales sacrificados por sobreanestesia con cloroformo. Algunas de estas cepas se mantienen aún hasta 14 pases en hámsteres. Los animales que no desarrollaron lesiones fueron mantenidos en observación hasta doce meses y luego fueron sacrificados.

\section{Resultados}

\section{Pacientes, Lessiones y Edad de las Lesiones}

En la Tabla 1 se informó para pacientes masculinos y femeninos, la media etárea, la media del número de lesiones y la edad media de las mismas, en el momento de acudir a la consulta.

\section{Desarrollo de las Lesiones Tarsales en Hámsteres Controles y Experimentales}

Con material biópsico de los 50 pacientes, se inoculo 100 hámsteres.

Veinticuatro de cincuenta animales inoculados solamente con homogeneizado de biópsias de lesiones, desarrollaron induraciones con parásitos en una media de $11,75+7,3$ semanas, para un $48 \%$ de inoculaciones positivas. De los 26 hámsteres que no desarrollaron lesiones, nueve murieron antes de ocho semanas probablemente por causa de contaminación bacteriana. Los diecisiete restantes se mantuvieron sanos y negativos durante mas de seis meses. En los tarsos izquierdos no se observaron lesiones de ningún tipo.

De los $\mathbf{5 0}$ hámsteres inoculados con la mezcla de triturado de material biópsico y lisado de glándulas salivales de Lu. youngi, 46

Tabia 1. Edad de los pacientes con el número de lesiones por paclente y tlempo de evolución de las mismas.

\begin{tabular}{lcccc} 
Sexo & No. & $\begin{array}{c}\text { Edad en } \\
\text { años }\end{array}$ & $\begin{array}{c}\text { No. de } \\
\text { lesiones } \chi\end{array}$ & $\begin{array}{c}\text { Edad de las } \\
\text { leslones (meses) } \chi\end{array}$ \\
\hline Varones & 25 & $30,8 \pm 14,4$ & $1,52 \pm 0,8$ & $2,48 \pm 1,1$ \\
Hembras & 25 & $31,1 \pm 22,6$ & $1,32 \pm 0,6$ & $2,30 \pm 1,5$
\end{tabular}


desarrollaron lesiones tempranas en una media de $3,3+0,9$ semanas y fueron sacrificados a medida que exhibieron granulomas. La gran mayoría de los animales con lesiones mostraron parásitos para un $92 \%$ de inoculaciones positivas. Cuatro hámsteres que se comportaron como animales negativos hasta los seis meses de observación después de la inoculación, fueron sacrificados. La improntas de piel tarsal de estos animales no mostraron amastigotos.

En la Tabla 2 se resumió esta información, destacando que la incorporacion de lisado de glándulas salivales de $L u$. youngi, en inócuios de parásitos de lesiones de pacientes de misma área de distribución del vector, eleva la infectividad de los parásitos en los hámsteres hasta un $92 \%$ de los casos, en comparación con un $48 \%$ de positividad en las inoculaciones con homogeneizado de tejido de las lesiones sin lisado de glándulas salivales. Se destaca además el extraordinario acortamiento del periodo de incubación para la formación del granuloma parasitario en los animales experimentales, hasta menos de un mes. En cambio, en los hámsteres controles, la duración media del periodo prepatente para la aparición de una induración por granuloma parasitario fue de tres meses.

\section{Edad de los Lisados de Glándulas Salivales y la Duración de la Prepatencia de los Granulomas Parasitarios Producidos}

Se usó seis lotes de glándulas salivales de 10 hembras de $L u$. youngi homogeneizados en 1,0 $\mathrm{ml}$ de solución isotónica. En la Tabla 3 se informó sobre las fechas de preparación de los lotes, el tiempo medio en semanas de su conservación a $-8^{\circ} \mathrm{C}$ para el momento de uso en mezclas con homogeneizados de lesiones cutáneas y el periodo medio de la aparición de lesiones tarsales, en semanas, en los hámsteres inoculados

Se utilizó lisados de glándulas salivales de una hasta diecinueve semanas en congelación a $-8^{\circ} \mathrm{C}$. Lisados de glándulas salivales mantenidos durante $4,1 \pm 2,9$ hasta $17,8 \pm 0,9$ samanas, potenciaron granulomas con $3,4 \pm 0,7$ hasta 3,6 $\pm 0,9$ semanas de prepatencia.

\section{Discusión}

El hamster dorado (Cricetus auratus) es altamente susceptible a la inoculación con amastigotos de Leishmania spp. del Continente Americano C. Wilson et al. ${ }^{16}, 1979$ ). La inoculación intradérmica de $10^{2}$ amastigotos de $L$. braziliensis produjo lesiones visibles después de 30 días y el porcentaje de infecciones fue relativamente alto $(88,95 \%)$. No obstante, la inoculación subcutánea de hámsteres con parásitos de material biópsico de 38 pacientes con lesiones positivas, todos de la Region de los Andes, produjo un 47,4\% infecciones (Valera et al. ${ }^{15}, 1978$ ). La inoculación subcutánea de $2,5 \times 10^{4}$ amastigotos de un aislado local de L. braziliensis en los tarsos de diez hámsteres, produjo lesiones permanentes en todos a los 30 días de inoculados (Rezzano \& Scorza ${ }^{7}, 1985$ ).

El aislamiento directo de parásitos de lesiones positivas por cultivo de aspirados en medio de Schneider, ha sido exitoso en $83 \%$ de 209 casos de leishmaniasis cutánea localizada de Guatemala (Navin et al. ${ }^{5}, 1990$ ).

Sanchez et al. ${ }^{9}$ (1992) aislaron parásitos, por cultivo de aspirados de lesiones en once de diecisiete pacientes infectados en Panarná (65\%), en tanto que el cultivo de piel de los mismos casos, fue positivo para un $41 \%$ de los pacientes parasitológicamente comprobados. En ninguno de estos dos trabajos sobre epidemiología y diagnóstico se hizo la inoculación de material clínico en hámsteres para aislar los parásitos.

La inoculación de hámsteres con promastigotos de cinco diferentes cepas en cultivo, como una medida de seguridad para preservar cepas de lesiones de pacientes con lesiones cutáneas (Gomez et al. ${ }^{1}, 1987$ ), produjo lesiones de muy lento desarrollo sugiriéndo ello que la evolución de tales parásitos del Ecuador en hámsteres, es un proceso extremadamente lento.

Tabla 2. Desarrollo de lesiones tarsales en hamsteres inoculados con material biopslco, con y sin lisado de glándulas salivales de L. youngi.

\begin{tabular}{lcccc}
$\begin{array}{l}\text { Hamsteres } \\
\text { inoculados }\end{array}$ & No. & $\begin{array}{c}\text { Infecciones } \\
\text { positivas }\end{array}$ & $\begin{array}{c}\text { Tiempo medio } \\
\text { de Inoculación } \\
\text { (semanas) } \chi\end{array}$ & $\begin{array}{c}\text { Mortalidad } \\
\text { espontánea }\end{array}$ \\
\hline Con llsados & 50 & 46 & $3,3 \pm 0,9$ & 0 \\
Sin lisado & 50 & 24 & $11,8 \pm 7,3$ & 9
\end{tabular}


Tabla 3. Tiempo de crlopresevación de los lisados de glándulas salivales de L. youngiy peziodo de prepatencia de los granulomas producidos en hamsteres experimentales.

\begin{tabular}{lccc} 
Lote & $\begin{array}{c}\text { Fecha } \\
\text { de preparación }\end{array}$ & $\begin{array}{c}\text { Crioconservación } \\
\text { (semanas) } \chi\end{array}$ & $\begin{array}{c}\text { Prepatencia } \\
\text { (semanas) } \chi\end{array}$ \\
\hline I & $28-5-90$ & $4,1 \pm 2,9(n: 10)$ & $3,4 \pm 0,7(n: 10)$ \\
II & $10-9-90$ & $5,6 \pm 1,96(n: 10)$ & $2,75 \pm 0,9(n: 8)$ \\
III & $10-9-90$ & $17,8 \pm 0,9(n: 8)$ & $3,6 \pm 0,92(n: 8)$ \\
IV & $10-9-90$ & $6,7 \pm 3,0(n: 10)$ & $3,5 \pm 1,1(n: 10)$ \\
V & $01-2-91$ & $13,4 \pm 3,15(n: 7)$ & $3,0 \pm 0,6(n: 7)$ \\
VI & $03-3-93$ & $8,5 \pm 5,0(n: 6)$ & $2,6 \pm 0,4(n: 3)$
\end{tabular}

En casos de Ieishmaniasis cutánea canina americana de Rio Janeiro (Pirmez et al $^{6}$., 1988), el cultivo in vitro de parásitos de biopsias de 35 perros naturalmente infectados fué posible para 28 animales ( $80 \%$ ), en tanto que la demostración de los parásitos en la piel, por método directo, ocurrío en 32 casos ( $91 \%$ ).

Nuestros hallazgos sobre aislamiento in vivo de cepas de L. braziliensis provenientes de casos cutáneos localizados, inoculando hámsteres machos con homogeneizado de material biópsico de lesiones mezclado con lisado glándulas salivales del vector de la localidad, demuestra la efectividad de esta técnica de aislarniento, cuando se la compara con la tradicional inoculación de hámsteres con homogeneizados de lesiones o con formas de cultivo in vitro.

La técnica de aislamiento in vivo de $L$. braziliensis, utilizando lisado de glándulas salivales como adyuvante para incrementar su infectividad en hámsteres, no solamente constituye una técnica de seguro resultado, sitno reduce el tiempo para el desarrollo de la infección, convirtiéndose en un procedimiento útil en condiciones de campo para localidades endémicas, donde los parásitos y sus vectores están presentes.

Hace setenta años (Smyly \& Young ${ }^{13}$ 1924), se demostraró la utilidad del hamster para el aislamiento de $L$. donovani a partir de la inoculación intraperitoneal de material de punción esplénica de un caso mortal, originario de China. Desde entonces, el hamster constituye un modelo susceptible para el aislamiento y conservación in vivo de estos parásitos. En este caso, la adición de lisado de glándula salival de flebótomos al inóculo, duplica el rendimiento de cepas por aislar y reduce considerablemente desde 3 meses hasta 3 semanas, el período de espera para el desarrolio de las lesiones. La actividad del factor salival que incrementa la infectividad de los amastigotos de lesiones cutáneas, no parece alterarse durante cuatro meses a $-8^{\circ} \mathrm{C}$.

\section{Conclusiones}

Se demuestra la existencia de un factor incrementador de la infectividad de cepas de $L$. braziliensis en el lisado de glándulas salivales de Lutzomyia youngi, confirmándose hallazgos originales hechos con $L$. major y Lu. longipalpis (Titus \& Ribeiro ${ }^{14}, 1988$ ).

La inoculación en hámsteres de homogeneizado de lesiones clínicas de 50 pacientes con leishmeniasis tegumentaria de la ciudad de Trujillo (Venezuela), mezclados con el equivalente al lisado de una glándula salival de $L u$. youngi, produjo lesiones tarsales en el $92 \%$ de las inoculaciones con una media de tres semanas de prepatencia. La inoculación de los mismos homogeneizados sin el lisado de glándula salival, produjo infecciones en el $48 \%$ de los ensayos con una media de 12 semanas para los periodos prepatentes.

Se considera de gran utilidad el uso del lisado de glándulas salivales de flebótomos para incrementar el éxito de las inoculaciones de amastigotos de lesiones clínicas en hámsteres, acortandose considerablemente la duración del períođo prepatente.

\section{Agradecimiento}

Los autores agradecen al técnico de Laboratorio Sr. Armando Torres, por su colaboración con el manejo de los animales experimentales.

\section{Referencias Bibliográficas}

1. GOMEZ, E. A. et al. Parasitology. 1. Leishmania isolates fron bumans. In: Studies on New World Leishmaniasis and its transmission, with particular reference to Ecuador, Y. Hashiguch, Kyowa Printing \& Co., 1987. p. 44-51.

2. JAMES, A.\& ROSSIGNOL, P. Mosquito salivary giands: parasitological and molecular aspects, Parasitol Today, 7: 267-71, 1991 .

3. LAURENTI, M. D. et al. inflamatory response it the 
subcutaneous inoculation site in $L$. (L) chagasi infection with Lutzomyia salivary gland lysates. Mem. Inst. Oswaldo Cruz, 87 (Supl 2), 1992.

4. MARQUEZ, M. \& SCORZA, J, V. Criterios de nuliparidad y de paridad en Lutzomyia townsendi (Ortiz, 1959) del Occidente de Venezuela. Mem. Inst. Oswaldo Cruz, 77: $229-461982$.

5. NAVIN, T. et al. Cutaneous leishmaniasis in Guatemala: comparison of diagnostic methods. Am. J. Trop. Med. Hyg.,42: 36-42, 1990.

6. PIRMEZ, C. et al. Canine American cutaneous leishmaniasis: clinical and inmunological study in dogs naturally infected with Leishmania braziliensis braziliensis in an endemica area of Rio de Janeiro, Brazil. Am. J. Trop. Med. Hyg., 38: 52 - 8, 1988.

7. REZZANO, S. \& SCORZA, J. V. Comportamiento de Leishmania chagasi, L mexicana y $L$. brazililensis en hámsteres machos inoculados subcutaneamente. Bol. Dir. Malarial. y Saneam. Amb., 25 (3/4): 59 . $66,1985$.

8. ROJAS, E. \& SCORZA, J. V. Metacíclicos de Leishmania mexicana experimentalmente infectada. Parassitologí, 33 (Supl 1): 493 - 500, 1991.

9. SANCHEZ, J. V. et al. Epidemiologic investigation of an outbreak of cutaneous leishmaniasis in a defined geoqraphic focus of transmission. Am. J. Trop. Med.
Hyg., $47: 47 \cdot 54,1992$.

10. SCORZA, J, V, et al. Hallazgo de Lutzomyia townsendi (Ortiz, 1959) naturaltnente infectada con Leishmania braziliensis en el area suburbana de Trujillo. Bol. Dir. Malariol. y Saneam. Amb., 24: 21-8, 1984.

11.SCORZA, J, V, et al. Encuesta epidemiologica sobre Leishmaniasis cutánea urbana en la ciudad de Trujillo, Venezuela. Bol. Dir. Malariol. y Saneam. Amb., 25: $73.81,1985$.

12. SCORZA, J.V. \& ROJAS, E. La leishmaniasis tagumentaria venezolana: problemática contemporánea en el Estado Trujillo: soluciones. Bol. Dir. Malar. Dir. Malariol. Saneam. Amb., 30: 1-6, 1990.

13. SMYLY, H. J. \& YOUNG, CH. N. The experimental transmission of leishmaniasis to animals. Proc. Soc. Exp. Biol. Med., 21: 354-6, 1924.

14. TITUS, R. \& RIBEIRO, J. Salivary gland lysates from the sanfly Lutzomyia longipalpis enhance Leishmania infectivity. Science, 239: $1306-8,1988$.

15. VALERA, M. et al. Cincuenta y seis casos de leishmaniasis tegumentaria en la cuenca de los ríos Chama-Mocoties (Estado Mérida, Venezuela) , Bol. Dir. Malarint y Saneam. Amb., 28: 238-47, 1978.

16. WILSON, R, et al, Leishmania braziliensis and Leishmania mexicana: experimental cutaneous infections in goiden hamsters. Exp. Parasitol., 47: 270-83, 1997.

\section{Abstract}

Homogenized biopsy tissue from the cutaneous leishmaniasis lesions of 50 patients from Trulilo, Venezuela, were inoculated subcutaneously into the tarsi of male hamsters. Homogenized tissue either alone or mixed with salivary gland lysates of Lutzomyia youngi were used for inoculation. Homogenized tissue alone yiejded $58.5 \%$ of infections with a mean of twelve weeks for prepatency, while those mixed with sandfly lysate resulted in $92 \%$ of infections with a mean prepatency of three wesks.

Leishmania brazilienses, pathogenicity. Psychodidae. Salivary glands. 